\title{
ZAP70-Related SCID: Non-Redundant Dual Functions of the ZAP70 Catalytic and Scaffolding Regions
}

\section{Noah Isakov*}

The Shraga Segal Department of Microbiology and Immunology, Faculty of Health Sciences and the Cancer Research Center, Ben Gurion University of the Negev, P.O.B. 653, Beer Sheva 84105, Israel

Primary Severe Combined Immunodeficiency (SCID) is a form of heritable immunodeficiency, characterized by impaired adaptive immune responses [1]. It includes a group of genetic disorders originated by defects in one of several different genes that are critical for $\mathrm{T}$ lymphocyte production and/or function and involve defects in $\mathrm{B}$ lymphocytes as a primary or secondary cause [2].

The most common type of SCID is linked to the X chromosome (X-SCID), and therefore affects only males [3,4]. The X-SCID males possess mutations in the interleukin-2 (IL-2) receptor gamma chain gene (IL-2R) encoding a protein that is shared by at least six different receptors for interleukins, including IL-2 and IL-4. These receptors direct the development and maturation of $\mathrm{T}$ and $\mathrm{B}$ lymphocyte subtypes and help regulate the entire adaptive immune system.

Other forms of SCID follow an autosomal recessive inheritance pattern that affects males and females equally. Among them, a relatively rare genetic disorder is caused by mutations in a gene encoding the $\mathrm{T}$ cell antigen receptor (TCR)/CD3-zeta chain $(\mathrm{CD} 3 \zeta)$ associated protein of $70 \mathrm{kDa}$ (termed ZAP70) [5-7], which is reflected by abnormal TCR signaling.

ZAP70-related SCID was first described in a patient of Mennonite descent with $\mathrm{CD} 8^{+}$lymphocytopenia and normal numbers of $\mathrm{CD} 4^{+} \mathrm{T}$ cells that did not proliferate in response to mitogenic stimulation [5-8]. A variety of distinct mutations in ZAP70 were identified in different patients, where the type of mutation determined the severity of the immunodeficiency $[9,10]$. Affected children present in the first year of life with recurrent bacterial, viral, and opportunistic infections, do not usually survive past their second year without hematopoietic stem cell transplantation.

ZAP70 is a non-receptor protein tyrosine kinase (PTK) that plays a critical role in TCR-linked signal transduction leading to $\mathrm{T}$ cell differentiation and maturation and acquisition of effector function. It was initially identified as a tyrosine phosphorylated protein with a molecular mass of $70 \mathrm{kDa}$ that associates with the $\mathrm{CD} 3 \zeta$ chain of activated T cells $[11,12]$. The transient binding of ZAP70 to CD3 $\zeta$ involves the ZAP70 tandem SH2 domains, which directly interact with phosphorylated tyrosine residues within the immunoreceptor tyrosinebased activation motifs (ITAMs) in the $\mathrm{CD} 3 \zeta$ subunit [13].

The $\mathrm{CD} 3 \zeta$ cytoplasmic tail possesses three copies of ITAMs, each containing two tyrosine residues critical for its function. TCR engagement by peptide-bound MHC molecules expressed on the surface of antigen-presenting cells (APC) stimulates Lck, a member

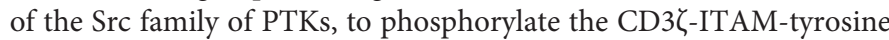
residues. The phosphorylated ITAMs serve as high affinity binding sites for ZAP70, thereby enabling its recruitment to T cell-APC contact area, also termed the immunological synapse [14-17]. The tyrosine phosphorylated $\mathrm{CD} 3 \zeta$-bound ZAP70 undergoes phosphorylation by Lck as well as autophosphorylation on specific tyrosine residues, which alter its conformation and convert it into an active enzyme [18]. The activated ZAP70 then phosphorylates specific downstream molecules [19-22], leading to calcium mobilization, activation of Ras GTPase and rearrangement of the actin cytoskeleton. These transient intracellular signals permit the activation of selected transcription factors that promote the proliferation and differentiation of $\mathrm{T}$ cells.

Analysis of the phosphorylation sites of ZAP-70 and their impact on the function of the molecule demonstrated that phosphorylation of Tyr319, Tyr492 and Tyr493 serves to regulate the ZAP70 catalytic activity [23-25]. However, in vivo activation of T cells results in ZAP70 phosphorylation on additional tyrosine residues [26,27] which may also function as putative docking sites for $\mathrm{SH} 2$-containing proteins. ZAP70 Tyr315 was reported to serve as a binding site for members of the Crk family of adaptor proteins $[27,28]$. Furthermore, the CrkII-SH3 domain can interact with a variety of proteins that possess poly-proline rich regions [29], thereby recruiting additional effector molecules to the site of the engaged TCR. One CrkII-SH3 binding partner is the guanine nucleotide exchange factor, $\mathrm{C} 3 \mathrm{G}$, which among other molecules, regulates the GTPase Rap1 [30-32]. Activation of Rap1 increases the inside-out signaling pathway that relays signals to the integrin LFA-1, increasing its affinity to ICAM1, there by augmenting LFA-1/ICAM-1mediated $\mathrm{T}$ cell adhesion.

The above information and additional published studies indicated that ZAP70 possesses a catalytic region and a separate protein-protein interaction (or scaffolding) region. Since distinct protein modules within a single molecule might operate in a cooperative manner, or independent of each other [33], it was of interest to decipher the relationships between these two regions within the ZAP70 molecule.

A recent study by Au-Yeung et al. [34] has solved this question by showing that under certain conditions, the ZAP70 protein exhibits biological functions in regulatory $\mathrm{T}$ cells $\left(\mathrm{T}_{\mathrm{reg}}\right)$ that are independent of the ZAP70 catalytic activity.

To investigate the role of catalytically inactive ZAP70 in normal naïve and mature T cells, the authors have utilized a ZAP70-deficient mouse line in which they expressed a ZAP70 mutant transgene that retains catalytic activity yet can also be inhibited by a PP1 inhibitor analog, termed 3-MB-PP1, a small-molecule kinase inhibitor [35]. The mutated analog-sensitive ZAP70 protein, termed ZAP70 (AS), possesses a methionine-to alanine substitution at position 414 in the ATP-binding domain, which allows it to accommodate the 3-MB-PP1 inhibitor. In addition, the 3-MB-PP1 molecule was found to specifically

*Corresponding author: Noah Isakov, The Shraga Segal Department of Microbiology and Immunology, Ben-Gurion University, Beer-Sheva, Israel, Tel: 972-8-6477267; Fax: 972-8-6477626; E-mail: noah@bgu.ac.il

Received March 21, 2012; Accepted March 24, 2012; Published March 28, 2012

Citation: Isakov N (2012) ZAP70-Related SCID: Non-Redundant Dual Functions of the ZAP70 Catalytic and Scaffolding Regions. J Clinic Case Reports 2:e113. doi:10.4172/2165-7920.1000e113

Copyright: (C) 2012 Isakov N. This is an open-access article distributed under the terms of the Creative Commons Attribution License, which permits unrestricted use, distribution, and reproduction in any medium, provided the original author and source are credited. 
inhibit the ZAP70 (AS) catalytic activity, and did not affect wild-type ZAP70 or other Src- or Tec-family PTKs [36].

When testing early activation events in ZAP70(AS) and control ZAP70 ${ }^{+/-} \mathrm{CD}^{+} \mathrm{T}$ cells stimulated by TCR/CD3 crosslinking, both cell types responded by a robust increase in the intracellular free $\mathrm{Ca}^{2+}$ concentration $\left[\mathrm{Ca}^{2+}\right]$ and phosphorylation and activation of the Erk MAPK. However, when TCR/CD3 crosslinking antibodies were added to the cultured cells together with the 3-MB-PP1 inhibitor, a dose-dependent inhibition of $\mathrm{Ca}^{2+}$ mobilization and Erk activation was observed in $Z A P 70$ (AS), but not in $Z A P 70^{+/-} \mathrm{CD} 4^{+} \mathrm{T}$ cells. In addition, $Z A P 70(\mathrm{AS})$ and control $Z A P 70^{+/-} \mathrm{CD} 4^{+} \mathrm{T}$ cells responded to TCR/CD3 plus CD28 crosslinking by strong proliferation, while $Z A P 70(\mathrm{AS})$ but not $Z A P 70^{+-} \mathrm{CD} 4^{+} \mathrm{T}$ cell proliferation was inhibited by 3-MB-PP1. These results suggested that the catalytic activity of ZAP70 is required for both early and late activation of mature naïve $\mathrm{CD} 4^{+} \mathrm{T}$ cells.

Similar studies performed in antigen-primed T cells demonstrated that interferon $\gamma$ (IFN-) and IL-10 (IL-10) cytokine production by antigen-challenged $\mathrm{T}_{\mathrm{H}} 1$ and $\mathrm{T}_{\mathrm{H}} 2 \mathrm{CD} 4^{+}$cells, respectively, require the catalytic activity of ZAP70. Furthermore, ZAP70 catalytic activity was required for the cytotoxic activity of primed alloreactive $\mathrm{CD} 8^{+} \mathrm{T}$ cells, and for their ability to respond in tumor necrosis factor (TNF) production.

A surprise came when the requirement for the ZAP70 catalytic activity was tested in the suppressive response of $\mathrm{CD} 4^{+} \mathrm{CD} 25^{+} \mathrm{T}_{\text {reg }}$ cells [34]. In this assay, Au-Yeung et al. [34] have shown that TCR/ CD3-stimulated Zap70(AS) $\mathrm{T}_{\text {reg }}$ cells that are cocultured with Zap70+$\mathrm{CD}^{+}{ }^{+} \mathrm{CD} 25^{-}$conventional $\mathrm{T}$ cells $\left(\mathrm{T}_{\text {conv }}\right.$ cells) have led to suppression of the proliferative response of $Z a p 70^{+/-} \mathrm{T}_{\text {conv }}$ cells. However, when the suppressive activity of Zap70 (AS) $\mathrm{T}_{\text {reg }}$ cells was tested, the cells exhibited a similar inhibition of proliferation of $Z a p 70^{+-} \mathrm{T}_{\text {conv }}$ cells in the absence but also in the presence of 3-MB-PP1, even when using 3-MB-PP1 concentrations that inhibited the anti-TCR/CD3-induced proliferation of Zap70 (AS) $\mathrm{T}_{\text {conv }}$ cells. Although the TCR/CD3induced increase in $\left[\mathrm{Ca}^{2+}\right]$ and Erk activation in Zap70(AS) $\mathrm{T}_{\text {reg }}$ cells were sensitive to suppression by $3-\mathrm{MB}-\mathrm{PP} 1$, the activation-induced phosphorylation of Tyr319 and Tyr493 were not affected, apparently because they serve as substrates for phosphorylation by Lck, which is insensitive to 3-MB-PP1.

The results by Au-Yeung et al. [34] support previous findings showing that tyrosine phosphorylated ZAP70 can act as a scaffolding protein $[27,28,37,38]$, and suggest that this activity is independent of the ZAP70 catalytic activity.

Au-Yeung et al. [34] have further demonstrated that CrkII and C3G coimmunoprecipitate with activated ZAP70 from Zap70 (AS) $\mathrm{T}_{\text {reg }}$ cells, even in the presence of 3-MB-PP1, and that activation of the downstream effector molecules, C3G and Rap1, was also independent of the catalytic activity of ZAP70 [38]. Furthermore, TCR/CD3-induced adhesion of Zap70 (AS) CD4 ${ }^{+} \mathrm{T}$ cells to ICAM-1-coated surface was not sensitive to inhibition by $3-\mathrm{MB}-\mathrm{PP} 1$, suggesting that the TCR/CD3induced inside-out signaling that regulate $\mathrm{T}$ cell adhesion requires the scaffolding function of ZAP70, but is independent of the ZAP70 catalytic activity. The results indicate that ZAP70 is a candidate drug target in autoimmune diseases and allograft rejection, and suggest that different ZAP70-specific drugs may vary in their ability to modulate responses of distinct $\mathrm{T}$ cell subtypes.

\section{Acknowledgement}

Work in our laboratory is funded in part by the USA-Israel Binational Science Foundation and the Israel Science Foundation administered by the Israel Academy of Science and Humanities. N.I. holds the Joseph H. Krupp Chair in Cancer Immunobiology.

\section{References}

1. Buckley RH (1992) Immunodeficiency diseases. JAMA 268: 2797-2806.

2. Fischer A (1993) Primary T-cell immunodeficiencies. Curr opin immunol 5: 569578.

3. Kinnon C, Levinsky R (1992) The molecular basis of X-linked immunodeficiency disease. J Inherit Metab Dis 15: 674-682.

4. Puck JM (1993) X-linked immunodeficiencies. Advances in human genetics 21 107-144.

5. Arpaia E, Shahar M, Dadi H, Cohen A, Roifman CM (1994) Defective T cell receptor signaling and $C D 8+$ thymic selection in humans lacking zap-70 kinase. Cell 76: 947-958.

6. Chan AC, Kadlecek TA, Elder ME, Filipovich AH, Kuo WL, et al. (1994) ZAP-70 deficiency in an autosomal recessive form of severe combined immunodeficiency. Science 264:1599-1601.

7. Elder ME, Lin D, Clever J, Chan AC, Hope TJ, et al. (1994) Human severe combined immunodeficiency due to a defect in ZAP-70, a T cell tyrosine kinase. Science 264: 1596-1599.

8. Roifman CM, Hummel D, Martinez-Valdez H, Thorner P, Doherty PJ, et al (1989) Depletion of CD8+ cells in human thymic medulla results in selective immune deficiency. J Exp Med 170: 2177-2182.

9. Turul T, Tezcan I, Artac H, de Bruin-Versteeg S, Barendregt BH, et al. (2009) Clinical heterogeneity can hamper the diagnosis of patients with ZAP70 deficiency. Eur J Pediatr 168: 87-93.

10. Elder ME, Skoda-Smith S, Kadlecek TA, Wang F, Wu J, et al. (2001) Distinct $T$ cell developmental consequences in humans and mice expressing identical mutations in the DLAARN motif of ZAP-70. J Immunol 166: 656-661.

11. Chan AC, Iwashima M, Turck CW, Weiss A (1992) ZAP-70: a 70 kd proteintyrosine kinase that associates with the TCR zeta chain. Cell 71: 649-662.

12. Wange RL, Kong AN, Samelson LE (1992) A tyrosine-phosphorylated 70-kDa protein binds a photoaffinity analogue of ATP and associates with both the zeta chain and CD3 components of the activated T cell antigen receptor. J Biol Chem 267: 11685-11688.

13. Wange RL, Malek SN, Desiderio S, Samelson LE (1993) Tandem SH2 domains of ZAP-70 bind to T cell antigen receptor zeta and CD3 epsilon from activated Jurkat T cells. J Biol Chem 268: 19797-19801.

14. Isakov N, Wange RL, Burgess WH, Watts JD, Aebersold R, et al. (1995) ZAP70 binding specificity to $T$ cell receptor tyrosine-based activation motifs: the tandem SH2 domains of ZAP-70 bind distinct tyrosine-based activation motifs with varying affinity. J Exp Med 181: 375-380.

15. Vely F, Nunes JA, Malissen B, Hedgecock CJ (1997) Analysis of immunoreceptor tyrosine-based activation motif (ITAM) binding to ZAP-70 by surface plasmon resonance. Eur J Immunol 27: 3010-3014.

16. Neumeister EN, Zhu Y, Richard S, Terhorst C, Chan AC, et al. (1995) Binding of ZAP-70 to phosphorylated T-cell receptor zeta and eta enhances its autophosphorylation and generates specific binding sites for $\mathrm{SH} 2$ domaincontaining proteins. Mol Cell Biol 15: 3171-3178.

17. Qian D, Mollenauer MN, Weiss A (1996) Dominant-negative zeta-associated protein 70 inhibits T cell antigen receptor signaling. J Exp Med 183: 611-620.

18. van Oers NS, Killeen N, Weiss A (1996) Lck regulates the tyrosine phosphorylation of the $T$ cell receptor subunits and ZAP-70 in murine thymocytes. J Exp Med 183: 1053-1062.

19. Isakov N, Wange RL, Watts JD, Aebersold R, Samelson LE (1996) Purification and characterization of human ZAP-70 protein-tyrosine kinase from a baculovirus expression system. J Biol Chem 271: 15753-15761. 
Citation: Isakov N (2012) ZAP70-Related SCID: Non-Redundant Dual Functions of the ZAP70 Catalytic and Scaffolding Regions. J Clinic Case Reports 2:e113. doi:10.4172/2165-7920.1000e113

20. Watts JD, Brabb T, Bures EJ, Wange RL, Samelson LE, et al. (1996) Identification and characterization of a substrate specific for the $T$ cell protein tyrosine kinase ZAP-70. FEBS letters 398: 217-222.

21. Zhang W, Sloan-Lancaster J, Kitchen J, Trible RP, Samelson LE (1998) LAT: the ZAP-70 tyrosine kinase substrate that links $T$ cell receptor to cellular activation. Cell 92: 83-92

22. Bubeck Wardenburg J, Fu C, Jackman JK, Flotow H, Wilkinson SE, et al. (1996) Phosphorylation of SLP-76 by the ZAP-70 protein-tyrosine kinase is required for T-cell receptor function. J Biol Chem 271: 19641-19644.

23. Wange RL, Guitian R, Isakov N, Watts JD, Aebersold R, et al. (1995) Activating and inhibitory mutations in adjacent tyrosines in the kinase domain of ZAP-70. J Biol Chem 270: 18730-18733.

24. Mege D, Di Bartolo V, Germain V, Tuosto L, Michel F, et al. (1996) Mutation of tyrosines 492/493 in the kinase domain of ZAP-70 affects multiple T-cell receptor signaling pathways. J Biol Chem 271: 32644-32652.

25. Di Bartolo V, Mege D, Germain V, Pelosi M, Dufour E, et al. (1999) Tyrosine 319 , a newly identified phosphorylation site of ZAP-70, plays a critical role in T cell antigen receptor signaling. J Biol Chem 274: 6285-6294.

26. Watts JD, Affolter M, Krebs DL, Wange RL, Samelson LE, et al. (1994) Identification by electrospray ionization mass spectrometry of the sites of tyrosine phosphorylation induced in activated Jurkat $\mathrm{T}$ cells on the protein tyrosine kinase ZAP-70. J Biol Chem 269: 29520-29529.

27. Gelkop S, Gish GD, Babichev Y, Pawson T, Isakov N (2005) T cell activationinduced Crkll binding to the Zap70 protein tyrosine kinase is mediated by Lckdependent phosphorylation of Zap70 tyrosine 315. J Immunol 175: 8123-8132.

28. Gelkop S, Isakov N (1999) T cell activation stimulates the association of enzymatically active tyrosine-phosphorylated ZAP-70 with the Crk adapter proteins. J Biol Chem 274: 21519-21527.
29. Feller SM, Knudsen B, Hanafusa $\mathrm{H}$ (1995) Cellular proteins binding to the first Src homology 3 (SH3) domain of the proto-oncogene product c-Crk indicate Crk-specific signaling pathways. Oncogene 10: 1465-1473.

30. Gotoh T, Hattori S, Nakamura S, Kitayama H, Noda M, et al. (1995) Identification of Rap1 as a target for the Crk SH3 domain-binding guanine nucleotidereleasing factor C3G. Mol Cell Biol 15: 6746-6753.

31. Buensuceso CS, O'Toole TE (2000) The association of CRKII with C3G can be regulated by integrins and defines a novel means to regulate the mitogenactivated protein kinases. J Biol Chem 275: 13118-13125.

32. Zhang W, Shao Y, Fang D, Huang J, Jeon MS, et al. (2003) Negative regulation of $T$ cell antigen receptor-mediated Crk-L-C3G signaling and cell adhesion by Cbl-b. J Biol Chem 278: 23978-23983.

33. Pawson T (1995) Protein modules and signalling networks. Nature 373: 573 580

34. Au-Yeung BB, Levin SE, Zhang C, Hsu LY, Cheng DA, et al. (2010) A genetically selective inhibitor demonstrates a function for the kinase Zap70 in regulatory $T$ cells independent of its catalytic activity. Nat Immunol 11: 10851092.

35. Bishop AC, Shah K, Liu Y, Witucki L, Kung C, et al. (1998) Design of allelespecific inhibitors to probe protein kinase signaling. Curr Biol 8: 257-266.

36. Levin SE, Zhang C, Kadlecek TA, Shokat KM, Weiss A (2008) Inhibition of ZAP-70 kinase activity via an analog-sensitive allele blocks $T$ cell receptor and CD28 superagonist signaling. J Biol Chem 283: 15419-15430.

37. Sasahara Y, Rachid R, Byrne MJ, de la Fuente MA, Abraham RT, et al. (2002) Mechanism of recruitment of WASP to the immunological synapse and of its activation following TCR ligation. Mol Cell 10: 1269-1281.

38. Hsu LY, Tan YX, Xiao Z, Malissen M, Weiss A (2009) A hypomorphic allele of ZAP-70 reveals a distinct thymic threshold for autoimmune disease versus autoimmune reactivity. J Exp Med 206: 2527-2541. 